\title{
Benefits of Palmer T- Plate Osteosynthesis in Unstable Distal Radius Fracture Management
}

\author{
Muhammad Ayub Khan', Asad Khan Ghilzai², Syed Kamran Ali Shah ${ }^{1 *}$ and Muhammad Kazim Rahim \\ Najjad $^{1}$
}

${ }^{1}$ Department of Orthopedics, Liaquat National Hospital, Pakistan

${ }^{2}$ Trauma Orthopedic Clinic, Pakistan

Received: February 03, 2018; Published: February 16, 2018

*Corresponding author: Syed Kamran Ali Shah, Department of Orthopedics, Liaquat National Hospital, Karachi, Pakistan, Tel: 0322-3077485, Email: drkami1405@gmail.com

\begin{abstract}
Objective: To evaluate the functional outcome of unstable distal radius fracture in adults treated with palmer T-plate Osteosynthesis.

Methods: This Prospective observational study was conducted at department of orthopedic surgery, from November 2013 to October 2015. Total of 86 patients were registered in this study with acute fracture within 24 hours of injury. Physical and radiological examination was done. Patients had follow up at $2^{\text {nd }}, 6^{\text {th }}$, and $12^{\text {th }}$ week after operations. On follow up, patients was asked to answer DASH (Disability of arm shoulder and hand) Score questionnaire and observation made with respect to development of movement at $2^{\text {nd }}, 6^{\text {th }}$ and $12^{\text {th }}$ week after removal of splint. Movement at wrist was evaluated objectively with the elbow flexed to $90^{\circ}$ and the arm adducted, measurement carried by using goniometry. Outcome with DASH score $<50$ and goniometry angle's degree $>50$ will be considered as satisfactory.
\end{abstract}

Results: Satisfactory outcome (DASH <50) was observed in 60(69.77\%) patients. Outcomes with respect to age, gender, mode of admission and type of fractures were found statistically insignificant.

Conclusion: The palmer T-plate can produce reliable and acceptably good results in the treatment of unstable distal radius fractures without angle-stable screws up to now. We concluded that stable and early mobilization with good functional outcomes can be obtained with this type of Osteosynthesis.

Keywords: Distal radius fractures; Osteosynthesis; T-plate; DASH Score

Abbreviations: DASH: Disability of Arm, Shoulder and Hand; DRF: Distal radius fractures; SPSS: Statistical Package for Social Sciences

\section{Introduction}

Fractures of distal radius are among the commonest fractures of upper extremity, and it represents approximately one sixth of all fractures presented in emergency department. High velocity injury in young population is the common mechanism of injury such as road traffic accident, fall from height, injuries occurs during athletic activities but in elderly age group low energy mechanism is the leading cause of distal radius fractures such as a simple fall from a standing height [1]. On the basis of AO classification, distal radius fracture classified as extra-articular, partial-articular and complete articular fracture. Treatment of such fractures varies from simple cast immobilization to open reduction and internal fixation. Non displaced or minimally displaced intra and extra- articular as well as impacted stable fractures with acceptable minimum shortening can be treated adequately by closed method with cast or splint immobilization. Failure to achieve closed reduction or failed initial closed reduction in follow up often requires operative treatment $[2,3]$. It is documented that displaced fractures of distal radius are challenging to treat with success by means of non operative methods [4].

In younger population, intra-articular fractures of distal radius comprise a distinct subgroup of fractures that are difficult to manage and are associated with high frequency of posttraumatic degenerative changes [5]. The main goal of treatment for such fractures is to restore painless motion and stability of wrist to allow daily activities of life without the propensity for future degenerative changes [6]. Principle of treatment is to restore articular congruity, normal palmer tilt, radial length and radial inclination. Osteosynthesis with small buttress plate is 
now recommended because loss of reduction with subluxation of the carpus is so common in distal radius fracture [7]. Open reduction and internal fixation can be expected to provide better functional outcomes in the early post operative period so it could be considered as option of treatment for patients requiring a faster return to function after the injury [8]. The wide range of plating techniques exist for fracture fixation of distal radius, new implants designs and plating strategies have made certain treatment options more attractive. Now multiple options available to the treating surgeon for distal radius fracture fixation like palmer plating, dorsal plating, dual column plating and fragment specific fracture fixation with multiple implants available for each form of plating. Although many of these decisions remain controversial and are often based on surgeon preference, a few generalizations can be made. Volar displaced intra-articular fractures are best treated with a volar buttress plate [9]. Open reduction and internal fixation with palmer T-plate in intra-articular fractures of distal radius showed favorable outcomes [10].

Our study has been conducted in locally to assess the functional outcome of unstable distal radius fracture in adults treated with palmer T-plate Osteosynthesis. Palmer T- plate can be the choice of implant for fixation of unstable distal radius fractures. Use palmer T- plate provides the best mode of anatomical reduction and in addition to this their buttress modes reduces and stabilize vertical shear intra-articular fractures through an antiglide effect [11]. The purpose for conducting this study is to achieve a validated data by assessing the postoperative range of motion by the use of validated DASH score (Disability of Arm, Shoulder and Hand) and assessment of degree of flexion \& extension at wrist post operatively. Evidence was provided of the validity, test-retest reliability, and responsiveness of the DASH \& confirming its usefulness across the whole extremity $[12,13]$. A very strong correlation was noted between DASH \& other scoring systems making it reliable in evaluating a subjective outcome. Range of flexion and extension which is most important function of wrist is evaluated.

\section{Materials and Methods}

This prospective observational study was conducted at the Department of Orthopedic Surgery, Liaquat National Hospital and Medical College, Karachi from November 2013 to October 2015. Patients were registered using a predesigned Performa. Approval from institutional ethical review committee was taken prior to commencement of the study. Formal informed written consent was obtained from patients registering in the study. Using a nonprobability, consecutive sampling technique 86 patients were registered for the study.

\section{Inclusion Criteria}

a) Patients with either sex.

b) Patients above age of 22 years and less than 50 yrs.

c) Patients reported at Orthopedics department with acute fracture less than 24 hours.

d) X-ray proven fractures of distal radius showing intraarticular fracture line. e) Patients with 23-B and its subtypes fracture according to AO Classification.

f) Closed fractures.

\section{Exclusion Criteria}

a) Pathological fractures.

b) Open Fractures.

c) Fractures with vascular injuries.

d) Patients with cognitive disorders not able to communicate effectively.

e) History of previous Injury to the same extremity.

f) Any other associated injury.

g) Patients with 23-C and its subtypes fracture according to AO Classification.

After meeting the inclusion and exclusion criteria, patients were included in the study. Physical and radiological examination was done by principal investigator. All patients were operated using a standard prescribed surgical technique by the experienced surgeon (having more than 5 yrs experience). Patients had follow up protocol at $2^{\text {nd }}, 6^{\text {th }}$, and $12^{\text {th }}$ week after operations. On follow up, patients were asked to answer DASH (Disability of arm shoulder and hand) score questionnaire and observation made with respect to development of movement at two weeks after removal of splint and patients were called for follow up twice with one month interval at $6^{\text {th }} \& 12^{\text {th }}$ weeks respectively. Movement at wrist was evaluated objectively with the elbow flexed to $90^{\circ}$ and the arm adducted.

Goniometry was used to measure the palmer flexion and dorsiflexion angles. The contra lateral normal wrist was used as control for each measurement. In the patient with bilateral fractures of the distal radius, the mean range of movement of the unaffected limbs of the other patients was used as the control value. Outcome with DASH score $<50$ and goniometry angle's degree $>50$ degree will be considered as satisfactory. Demographic, observational, and DASH score data was collected using a pre-designed proforma by the principal investigator. The DASH score is a 30 -item questionnaire on a 5-point ordinal scale (1-5), transformed to percentage, score range. Range is $0-100 \%$ which intended to assess the function and symptoms of persons with disorders of the upper limb.

\section{Interpretation of DASH scores}

A score of 0 indicates 'no disability' and score of 100 indicates 'severe disability. Outcome with DASH score $<50$ consider as satisfactory while DASH score $>50$ consider not-satisfactory.

\section{Method of Scoring}

DASH scale comprise of commands from daily living and patient him/herself mark score as per difficulty they feel in performing that command i.e. score 1 to 5
a) No Difficulty
b) Mild Difficulty 

c) Moderate Difficult
d) Severe Difficulty
e) Unable To Perform

\section{Goniometry}

Goniometer will be used to measure postoperative wrist flexion and extension. Palmer flexion and extension angle $>50$ degree as measured from goniometry was considered satisfactory. Confounding variables as well as bias was controlled by strictly following the exclusion criteria. Data was entered and analyzed through Statistical Package for Social Sciences (SPSS) Version 17. Mean and standard deviation were calculated for the quantitative variable i.e. age; palmer flexion, dorsiflexion, and DASH score. Frequency and percentage were calculated for qualitative variables like gender, mode of admission, type of fracture, and functional outcome (satisfactory/ unsatisfactory). Effect modifiers were controlled by stratification of age, gender, and type of fracture to observe the effect of these modifiers on outcome through chisquare test. $\mathrm{P}<0.05$ was taken as significant.

\section{Results}

A total of 86 patients reported at Orthopedics department with acute fracture less than 24 hours of injury. The average age of the patients was $33.02 \pm 6.73$ years. There were $62(72.09 \%)$ female and $24(27.91 \%)$ male. Regarding mode of admission, 52(60.47\%) were reported thorough emergency and 34(39.53\%) from outpatient department. Most of the common type of fracture was 23-B2 (55.81\%) followed by 23-B1 (25.58\%) and $18.6 \%$ cases were type 23-B3 fracture. The average palmer flexion, dorsiflexion was
$55.77 \pm 14.980$ and $58.77 \pm 17.750$ respectively while mean DASH score was $38.58 \pm 19.84$. Functional outcome after fixation of the unstable fracture of distal radius with palmer T-plate osteosynthesis showed satisfactory outcome (DASH <50) in $60(69.77 \%)$ cases while $26(30.23 \%)$ were unsatisfactory. Outcome with respect to age groups was satisfactory in $70 \%$ in 22 to 30 years of age patients, $60 \%$ satisfactory result noted in 31 to 40 years of age patients while $72.2 \%$ was satisfactory outcomes were observed in 40 to 50 years of age group patients. Significant difference was not observed among the age $(\mathrm{p}=0.87)$. With respect to gender, satisfactory outcome was $67.7 \%$ in female and $75 \%$ in male which is also insignificant. Similarly outcome was observed with respect to mode of admission and type of fracture but insignificant differences were observed as $\mathrm{p}$ value found to be statistically insignificant (Tables 1-5) and (Figure 1).

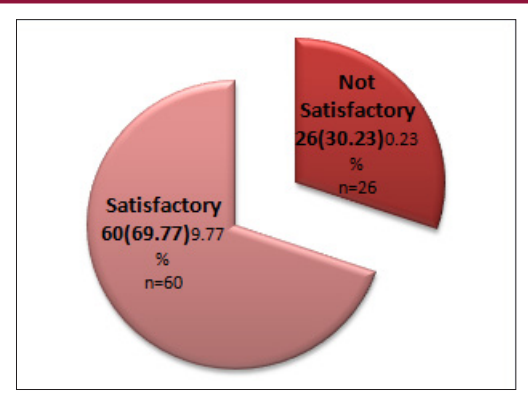

Figure 1: Functional Outcome of Unstable Distal Radius Fracture Treated with Palmer T-Plate Osteosynthesis at 12 Weeks Follow Up.

Outcome with DASH score $<50$ consider as satisfactory while DASH score $>50$ consider not satisfactory.

Table 1: Descriptive Statistics of Palmer Flexion, Dorsiflexion and Dash Score at 12 Weeks Follow Up.

\begin{tabular}{|c|c|c|c|c|}
\hline \multicolumn{2}{|c|}{ Descriptive Statistics } & Palmer flexion (Degree) & Dorsiflexion (Degree) & DASH Score \\
\hline Mean \pm SD & $55.77 \pm 14.98$ & $58.77 \pm 17.75$ & $38.58 \pm 19.84$ & \\
\hline \multirow{2}{*}{$\begin{array}{c}95 \% \text { Confidence Interval } \\
\text { for Mean }\end{array}$} & Lower Bound & 51.16 & 53.30 & 32.47 \\
\cline { 2 - 5 } & Upper Bound & 60.38 & 64.23 & 44.69 \\
\hline \multicolumn{2}{|c|}{ DASH= Disability of arm shoulder and hand SD= Standard Deviation } \\
\hline
\end{tabular}

Table 2: Functional Outcome of Unstable Distal Radius Fracture Treated with Palmer T-Plate Osteosynthesis at 12 Weeks Follow Up (by Age Groups).

\begin{tabular}{|c|c|c|c|}
\hline \multirow{2}{*}{ Age Groups (Years) } & \multicolumn{2}{|c|}{ Outcomes } & \multirow{2}{*}{ Total } \\
\cline { 2 - 4 } & Satisfactory & Not Satisfactory & 40 \\
\hline $22-30$ Years & $28(70 \%)$ & $12(30 \%)$ & 10 \\
\hline $31-40$ Years & $6(60 \%)$ & $4(40 \%)$ & 36 \\
\hline $40-50$ Years & $26(72.2 \%)$ & $10(27.8 \%)$ & 0.87 \\
\hline \multicolumn{3}{|c|}{ Chi-Square Test Applied } \\
\hline
\end{tabular}

Table 3: Functional Outcome of Unstable Distal Radius Fracture Treated with Palmer T-Plate Osteosynthesis at 12 Weeks Follow Up (by Gender).

\begin{tabular}{|c|c|c|c|c|}
\hline \multirow{2}{*}{ Gender } & \multicolumn{2}{|c|}{ Outcomes } & \multirow{2}{*}{ Total } \\
\cline { 2 - 4 } & Satisfactory & Not Satisfactory & 62 \\
\hline Female & $42(67.7 \%)$ & $20(32.3 \%)$ & 24 & 0.64 \\
\hline Male & $18(75 \%)$ & $6(25 \%)$ & Chi-Square Test Applied \\
\hline
\end{tabular}


Table 4: Functional Outcome of Unstable Distal Radius Fracture Treated with Palmer T-Plate Osteosynthesis at 12 Weeks Follow Up (by Mode of Admission).

\begin{tabular}{|c|c|c|c|}
\hline \multirow{2}{*}{ Mode of Admission } & \multicolumn{2}{|c|}{ Outcomes } & \multirow{2}{*}{ Total } \\
\cline { 2 - 4 } & Satisfactory & Not Satisfactory & 34 \\
\hline OPD & $22(64.7 \%)$ & $12(35.3 \%)$ & 52 \\
\hline Emergency & $38(73.1 \%)$ & $14(26.9 \%)$ & 0.55 \\
\hline \multicolumn{3}{|c|}{ Chi-Square Test Applied } \\
\hline
\end{tabular}

Table 5: Functional Outcome of Unstable Distal Radius Fracture Treated with Palmer T-Plate Osteosynthesis at 12 Weeks Follow Up (by Mode of Admission).

\begin{tabular}{|c|c|c|c|}
\hline \multirow{2}{*}{ Type of Fracture } & \multicolumn{2}{|c|}{ Outcomes } & \multirow{2}{*}{ Total } \\
\cline { 2 - 4 } & Satisfactory & Not Satisfactory & 22 \\
\hline $23-\mathrm{B} 1$ & $14(63.6 \%)$ & $8(36.4 \%)$ & 48 \\
\hline $23-\mathrm{B} 2$ & $36(75 \%)$ & $12(25 \%)$ & 16 \\
\hline $23-\mathrm{B} 3$ & $10(62.5 \%)$ & $6(37.5 \%)$ & 0.70 \\
\hline \multicolumn{3}{|c|}{ (Chi-Square Test Applied) } \\
\hline
\end{tabular}

\section{Discussion}

Distal radius fractures (DRF) occur more frequently than any other fracture. Various operating methods for distal radius fracture fixation have used by orthopedic surgeons, including K-wire fixation, external fixation and open reduction and internal fixation with different implants are well established and widely used [14]. External fixation with additional use of K-wires fixation to achieve stable fixation, may be associated with prolonged postoperative stiffness and pin tract infection and with loss of reduction. Dorsal plate Osteosynthesis may cause extensor tendons irritations and some time even rupture, so their removal is often necessary, in contrast volar plate can be left in place for most of cases [1517]. Several studies have conducted for the treatment unstable distal radius fracture and showed satisfactory results with each method but treatment of choice for such unstable fracture remain controversial. With the exception of a very recent study, not even randomized control trials could convincingly show better results for any of the procedures [16-19]. While dorsal plate used for treating unstable distal radius fracture, it requires exposure of the fragments, frequently spongioplasty, and usually removal of the implant later on. However, with the palmar approach for the reconstruction of the articular surface and restoration can easily be achieved with the T-plate.

Jupiter and Fernandez report shows operative treatment of 49 palmer marginal intra-articular fracture shows 31 excellent, 10 good and 8 with fair results [20]. Koenig KM in his study conclude that early internal fixation with volar plating is the preferred strategy in most scenarios [21]. In a prospective study a total of 124 unstable fractures of the distal radius were treated with a fixed angle palmar T-plate Using the functional outcome score according to Sarmiento, they obtained $15 \%$ excellent, $56 \%$ good, $28 \%$ fair and $1 \%$ poor results [22]. In Strohm et al. [23] study after reduction and plate Osteosynthesis they found no secondary displacement. Dumont C et al. [24] in a prospective study evaluate 200 patients functionally and radio logically and conclude that palmer $\mathrm{T}$ plate has produced reliable and good results in the treatment of unstable distal fractures of the radius without angle stable screws. Wright in his study concluded that the use of ORIF with a volar fixed-angle implant resulted in stable fixation of the distal articular fragments, allowing early postsurgical wrist motion [25]. Jupiter followed surgical management of 13 complex intra-articular (pilon) fractures of the distal radius was remarkably effective and only three patients had any residual functional problems [26].

S.G Pneumatocos studied 25 consecutive patients with volar plating of which 13 patients with intra- articular fracture distal radius shows good results while 9 patients with extra-articular fractures show excellent results [27]. Above mention author's studies had comparable or in positive association with our study as we noticed satisfactory outcome (DASH $<50)$ was observed in $60(69.77 \%)$ cases while 26(30.23\%) were unsatisfactory, and concluded that palmer T-plate could be the favorable method for fixing unstable distal radius fracture. In our study with respect to age, satisfactory outcome was observed in $70 \%$ of age group 22 to 30 years of age patients, $60 \%$ satisfactory result noted in 31 to 40 years of age patients while $72.2 \%$ satisfactory outcomes noted in 40 to 50 years of age group patients. Significant difference was not observed among the age $(\mathrm{p}=0.87)$. Dumont $\mathrm{C}$ et al in their study compared group 1 (younger than 60 years, $n=88$ ) vs. group 2 (older than 60 years, $n=78$ ). The patients' evaluation of the usability of the hand was normal in $56 \%$ and in $26.5 \%$ slightly reduced. $12.5 \%$ felt handicapped and $5 \%$ felt severely handicapped. Function according to Lidström: $23 \%$ excellent, $58 \%$ good, $15 \%$ fair and $4 \%$ poor results. Radiological results according to Lidström were excellent and good in $88.3 \%$ and fair in $11.7 \%$. Gartland and Werley score was excellent in $66 \%$, good in $24 \%$, fair in $6 \%$ and poor in $4 \%$. They also noted no significant difference between group 1 and group 2 in the age-depending results.

\section{Conclusion}

The palmer T-plate has produced reliable and good results in the treatment of unstable distal fractures of the radius without angle-stable screws up to now. This type of Osteosynthesis is 
stable and ensures early mobilization with good functional results postoperatively.

\section{References}

1. Egol AK, Koval KJ, Zuckerman JD. Handbook of Fractures ( $5^{\text {th }}$ Edn.).

2. Knirk JL, Jupiter JB (1986) Intra- articular fractures of the distal end of the radius in young adults. J Bone Joint Surg 68(5): 647-659.

3. Melone CP (1986) Open treatment for displaced articular fractures of the distal radius. Clin Orthop 202: 103-111.

4. Rodríguez MerchN EC (1998) Management of Comminuted Fractures of the Distal Radius in the Adult: Conservative or Surgical? Clin Orthop Relat Res 353: 53-62.

5. Knirk JL, Jupiter JB (1986) Intra- articular fractures of the distal end of the radius in young adults. J Bone Joint Surg Am 68(5): 647-659.

6. Bucholz RW, Heckman JD, Court-Brown CM Rockwood \& Green's Fractures in Adults (6 ${ }^{\text {th }}$ Edn.).

7. Campbell's Operative Orthopedics ( $11^{\text {th }}$ Edn.).

8. Rozental TD, Blazar PE, Franko OI, Chacko AT, Earp BE, et al. (2009) Functional Outcomes for Unstable Distal Radial Fractures Treated with Open Reduction and Internal Fixation or Closed Reduction and Percutaneous Fixation: A Prospective Randomized Trial. J Bone Joint Surgery 91(8): 1837-1846.

9. Swan K, Capo JT, Tan V (2003) Distal radius plating options. Current opinion in orthopedics 14(4): 238-244.

10. Rahmanzadeh R (1990) Treatment of distal radius fracture with plate osteosynthesis. Langenbecks Arch Chir Suppl II Verh Dtsch Ges Chir 1990: 657-661.

11. Nana AD, Joshi A, Lichtman DM (2005) Plating of the Distal Radius. J Am Acad Orthop Surg 13(3): 159-171.

12. Beaton DE, Katz JN, Fossel AH (2001) Measuring the whole or the parts? Validity, reliability, and responsiveness of the disabilities of the arm, shoulder and hand outcome measure in different regions of the upper extremity. J Hand Ther 14(2): 128-146.

13. Beaton DE, Davis AM, Hudak PL, Connell HP (2001) The DASH (disabilities of the arm, shoulder and hand) outcome measures: what do we know about it now?. Br J Hand Ther 6(4): 109-118.

14. Fernandez DL, Jupiter JB (2002) Fractures of the Distal Radius. A Practical Approach to Management. Springer, New York, USA.
15. Ruch DS, Papadonikolakis A (2006) Volar versus dorsal plating in the management of intra-articular distal radius fractures. J Hand Surg 31(1): 9-16.

16. Hahnloser D, Platz A, Amgwerd M, Trentz O (1999) Internal fixation of distal radius fractures with dorsal dislocation: pi-plate or two 1/4 tube plates? A prospective randomized study. J Trauma. 47(4): 760-765.

17. Chung KC, Petruska EA (2007) Treatment of unstable distal radial fractures with the volar locking plating system. Surgical technique. J Bone Joint Surg Am 89: 256-266.

18. Leung F, Tu YK, Chew WY, Chow SP (2008) Comparison of external and percutaneous pin fixation with plate fixation for intra-articular distal radial fractures. A randomized study. J Bone Joint Surg Am 90(1): 16-22.

19. Handoll HH, Madhok R (2003) Surgical interventions for treating distal radial fractures in adults. Cochrane Database Syst Rev 3: CD003209.

20. Jupiter JB, Fernandez DL, Toh CL (1996) Operative treatment of volar intra-articular fractures of the distal end of the radius. J Bone Joint Surg 78(12): 1817-1828.

21. Koenig KM, Davis GC, Grove MR, Tosteson AN, Koval KJ (2009) Is early internal fixation preferred to cast treatment for well - reduced unstable distal radial fractures? J Bone Joint Surg Am 91(9): 2086-2093.

22. Sakhaii M, Groenewold U, Klonz A, Reilmann H (2003) Results after palmar plate-osteosynthesis with angularly stable T-plate in 100 distal radius fractures: a prospective study. Unfallchirurg 106(4): 272-280.

23. Strohm PC, Müller CA, Helwig P, Mohr B, Südkamp NP (2007) Is the locking, $3.5 \mathrm{~mm}$ Palmar T-Plate the implant of choice for displaced distal radius fractures? Z Orthop Unfall 145(3): 331-337.

24. Dumont C, Fuchs M, Folwaczny EK, Heuermann C, Sturmer KM (2003) Results of palmer T-plate osteosynthesis in unstable fractures of the distal radius. Chirurg 74(9): 827-333.

25. Wright TW, Horodyski MB, Smith DW (2005) Functional Outcome of Unstable Distal Radius Fractures: ORIF with a Volar Fixed-Angle Tine Plate versus External Fixation. J Hand Surg 30(2): 289-299.

26. Jupiter JB, Lipton H (1993) The operative treatment of intra-articular fractures of the distal radius. Harvard Med Sch Boston Massachusetts 292: 48-61.

27. Pneumaticos SG (2007) Volar Plating for Displaced Fractures of the Distal Radius Osteo trauma care. 15: 104-109.
This work is licensed under Creative Commons Attribution 4.0 License

Submission Link: http://biomedres.us/submit-manuscript.php

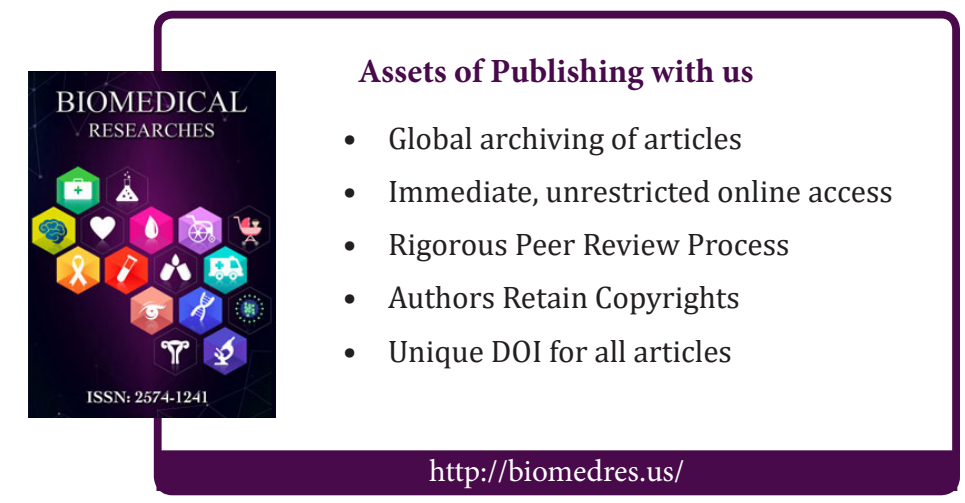

